\title{
THE ROLE OF SINGULAR VALUES OF MEASURED FREQUENCY RESPONSE FUNCTION MATRIX IN MODAL DAMPING ESTIMATION (PART I: THEORY)
}

\author{
Ferenc Pápai, István Szǘcs
}

Original scientific paper The singular value decomposition of the measured frequency response function matrix, as a very effective tool of experimental modal analysis is used over the last twenty-five years. The complex mode indication function has become a common numerical tool in processing experimental data. There are many references on the development of complex mode indication function including the enhanced mode indication function and its use together with the enhanced frequency response function to form spatial domain modal parameter estimation methods. Another amendment of the enhanced mode indicator function method is the extension of the single degree-of-freedom aspects of the complex mode indication function method to include a limited number of modes. In the paper, methods for estimation of damped eigen frequencies, modal damping and mode shapes are presented that are based on singular value decomposition of frequency response function matrix. It is shown how to obtain phase information for the complex mode indication function, in order to use the standard single degree-of-freedom modal parameter estimation methods. New aggregated frequency response function is introduced. A leastsquares approximation will be presented for eliminating the error caused by frequency discretization. Analytical models and examples taken from vehicle industry are also used to demonstrate applications of the aggregated frequency response function method and estimation of modal damping.

Keywords: complex mode indication function; damping estimate; experimental modal analysis; frequency response function matrix; singular values decomposition

\section{Uloga singularnih vrijednosti izmjerene matrice funkcije frekventnog odziva u procjeni modalnog prigušenja (Dio I: Teorija)}

Izvorni znanstveni članak

Dekompozicija singularnih vrijednosti izmjerene matrice funkcije frekventnog odziva se, kao vrlo učinkovit alat eksperimentalne modalne analize, koristi zadnjih dvadeset i pet godina. Funkcija indikacije kompleksnog moda postala je uobičajeni numerički alat u obradi eksperimentalnih podataka. Veliki je broj referenci o razvoju funkcije indikacije kompleksnog moda uključujući poboljšanu funkciju indikacije moda i njenu primjenu skupa s poboljšanom funkcijom frekventnog odgovora u razvoju metoda procjene modalnog parametra prostornog područja. Još jednu nadopunu poboljšanoj metodi funkcije indikatora moda predstavlja proširenje aspekata jednog stupnja slobode metode indikacije funkcije kompleksnog moda na ograničeni broj modova. U radu su predstavljene metode za procjenu prigušenih eigen frekvencija, modalnog prigušenja i oblika modova, zasnovane na dekompoziciji singularne vrijednosti matrice funkcije frekventnog odgovora. Pokazano je kako dobiti faznu informaciju za funkciju indikacije kompleksnog moda u svrhu primjene standardnih metoda procjene modalnim parametrom s jednim stupnjem slobode. Uvedena je novo dobivena funkcija frekventnog odziva. Pokazat će se aproksimacija najmanjih kvadrata za eliminiranje greške izazvane diskretizacijom frekvencije. Korišteni su također analitički modeli i primjeri iz industrije vozila u svrhu demonstracije primjene dobivene metode funkcije frekventnog odziva i procjene modalnog prigušenja.

Ključne riječi: dekompozicija singularnih vrijednosti; eksperimentalna modalna analiza; funkcija indikacije kompleksnog moda; matrica funkcije frekventnog odziva; procjena prigušenja

\section{Introduction}

There is an intention to develop an experimental modal analysis system that is generic and limits the user interactions. Both time- and frequency domain methods are unable to provide data without manual interaction. The critical point of the evaluation is to determine the number of dominating modes inside the measured frequency range, in other words to find out how many degrees of freedom does the analyzed structure have. This can only be successful, if a global aggregator function is available that is the basis of the peak-picking (PP). There are plenty of aggregator functions published in the literature.

In this paper a new complex valued aggregator frequency response function $(a F R F)$ is introduced that has the following properties:

- it is a complex function of frequency for the whole multi-degree-of-freedom (MDOF) system,

- $\quad$ each peak of its absolute value function indicates a mode, and the corresponding frequency of a peak approximates the damped natural frequency,

- this function contains phase information, thus every mode is represented as a modal circle on the Nyquist plot,

- it smoothers noise,
- the modal damping can be estimated with linear regression, not necessarily all points have to fall in the half-power bandwidth,

- it is successful even if data with rough frequency resolution is provided.

\section{Damped multiple-degree-of-freedom systems}

The equation of motion of a viscously damped system is expressed by

$$
\boldsymbol{M} \ddot{\boldsymbol{x}}+\boldsymbol{C} \dot{\boldsymbol{x}}+\boldsymbol{K} \boldsymbol{x}=\boldsymbol{f}(t),
$$

where $\boldsymbol{M}, \boldsymbol{C}, \boldsymbol{K}$ are the mass, damping and stiffness matrices respectively; $\boldsymbol{x}=\boldsymbol{x}(t)$ is the dynamic displacement response, $f(t)$ is the excitation.

The system matrix of Eq. (1) is

$\boldsymbol{Z}(\lambda)=\lambda^{2} \boldsymbol{M}+\lambda \boldsymbol{C}+\boldsymbol{K}$

The eigenvalues $\lambda_{i}=\delta_{i}+j v_{i},(i=1,2, \ldots, 2 N)$ of the system are complex quantities. The $\delta_{i}$ are the damping values, and $v_{i}$ are the damped natural frequencies, $j$ is the imaginary unit. The inverse of the $\boldsymbol{Z}(\lambda)$ is the 
$\boldsymbol{H}(\lambda)=\boldsymbol{Z}^{-1}(\lambda)$ transfer matrix. The $\boldsymbol{H}(\lambda)$ can be written in form [1]

$$
\boldsymbol{H}(\lambda)=\boldsymbol{X}(\lambda \boldsymbol{I}-\boldsymbol{\Lambda})^{-1} \boldsymbol{\Theta}^{-1} \boldsymbol{Y}^{T},
$$

where $\boldsymbol{X}_{N \times 2 N}, \boldsymbol{Y}_{2 N \times N}^{T}$ are the modal matrices, $\boldsymbol{\Lambda}_{2 N \times 2 N}$ is the spectral matrix (diagonal) contains the eigenvalues, $\boldsymbol{\Theta}_{2 N \times 2 N}$ is the eigenvector normalization matrix (diagonal). Partial fraction form of the transfer matrix is

$\boldsymbol{H}(\lambda)=\sum_{i=1}^{2 N} \frac{\vartheta_{i}^{-1} \boldsymbol{x}_{i} \boldsymbol{y}_{i}^{T}}{\lambda-\lambda_{i}}=\sum_{i=1}^{N}\left\{\frac{\vartheta_{i}^{-1} \boldsymbol{x}_{i} \boldsymbol{y}_{i}^{T}}{\lambda-\lambda_{i}}+\frac{\left(\vartheta_{i}^{*}\right)^{-1} \boldsymbol{x}_{i}^{*} \boldsymbol{y}_{i}^{H}}{\lambda-\lambda_{i}^{*}}\right\}$

Substitute $\lambda=j \omega$ in Eq. (4), we get the Frequency Response Function $(F R F)$ matrix

$$
\boldsymbol{H}(j \omega)=\sum_{i=1}^{2 N} \frac{\vartheta_{i}^{-1} \boldsymbol{x}_{i} \boldsymbol{y}_{i}^{T}}{j \omega-\lambda_{i}}=\sum_{i=1}^{N}\left\{\frac{\vartheta_{i}^{-1} \boldsymbol{x}_{i} \boldsymbol{y}_{i}^{T}}{j \omega-\lambda_{i}}+\frac{\left(\vartheta_{i}^{*}\right)^{-1} \boldsymbol{x}_{i}^{*} \boldsymbol{y}_{i}^{H}}{j \omega-\lambda_{i}^{*}}\right\}
$$

In case of symmetrical systems $\boldsymbol{X}=\boldsymbol{Y}$, hence the rightside eigenvectors $\boldsymbol{x}_{i}$ and left-side eigenvectors $\boldsymbol{y}_{i}$ are equal. Thus for symmetrical systems the $F R F$ matrix is,

$$
\begin{aligned}
& \boldsymbol{H}(j \omega)=\boldsymbol{X}(\lambda \boldsymbol{I}-\boldsymbol{\Lambda})^{-1} \boldsymbol{\Theta}^{-1} \boldsymbol{X}^{\mathrm{T}}, \\
& \boldsymbol{H}(j \omega)=\sum_{i=1}^{2 N} \frac{\vartheta_{i}^{-1} \boldsymbol{x}_{i} \boldsymbol{x}_{i}^{T}}{j \omega-\lambda_{i}}=\sum_{i=1}^{N}\left\{\frac{\vartheta_{i}^{-1} \boldsymbol{x}_{i} \boldsymbol{x}_{i}^{T}}{j \omega-\lambda_{i}}+\frac{\left(\vartheta_{i}^{*}\right)^{-1} \boldsymbol{x}_{i}^{*} \boldsymbol{x}_{i}^{H}}{j \omega-\lambda_{i}^{*}}\right\} .
\end{aligned}
$$

The FRF matrix describes the multiple input/multiple output relationship of the structure at each spectral line. $F R F$ matrix can be written in form

$$
\boldsymbol{H}(j \omega)=\sum_{i=1}^{2 N} \frac{\boldsymbol{P}_{i}}{j \omega-\lambda_{i}}=\sum_{i=1}^{N}\left\{\frac{\boldsymbol{P}_{i}}{j \omega-\lambda_{i}}+\frac{\boldsymbol{P}_{i}^{*}}{j \omega-\lambda_{i}^{*}}\right\},
$$

where $\boldsymbol{P}_{i}=\vartheta_{i}^{-1} \boldsymbol{x}_{i} \boldsymbol{x}_{i}^{T}$ is the $i^{\text {th }}$ residue matrix.

Another form of FRF matrix is

$$
\boldsymbol{H}(j \omega)=\boldsymbol{X}(j \omega \boldsymbol{I}-\boldsymbol{\Lambda})^{-1} \boldsymbol{L} .
$$

In this context the matrix $\boldsymbol{X}$ relates to the responses or displacements. This matrix is the modal vector matrix. The matrix $\boldsymbol{L}=\boldsymbol{\Theta}^{-1} \boldsymbol{X}^{T}$ relates to the inputs or the forces, that is the modal participation factor matrix. In the practice of experimental modal analysis methods the $F R F$ matrix in Eq. (9) is limited to

$$
\boldsymbol{H}(j \omega)_{N_{o} \times N_{i}}=\boldsymbol{X}_{N_{o} \times 2 N_{m}}(j \omega \boldsymbol{I}-\boldsymbol{\Lambda})_{2 N_{m} \times 2 N_{m}}^{-1} \boldsymbol{L}_{2 N_{m} \times N_{i}},
$$

where $N_{o}$ is the number of response points, $N_{i}$ is the number of excitation points, $N_{m}$ is the number of observable modes.
In absence of multiple roots, near resonance, as $\omega$ approaches the system pole $\lambda_{i}$ the quantity $\operatorname{abs}\left(1 /\left(j \omega-\lambda_{i}\right)\right)$ reaches a maximum. Since the quantities $\boldsymbol{X}_{N_{o} \times 2 N_{m}}$ and $\boldsymbol{L}_{2 N_{m} \times N_{i}}$ constant, the amplitude information of the frequency response matrix at a given location depends on these $1 /\left(j \omega-\lambda_{i}\right)$ terms.

A special case of damping matrix $\boldsymbol{C}$ is a general proportional damping matrix. If damping matrix that satisfies the condition

$$
\boldsymbol{C} \boldsymbol{M}^{-1} \boldsymbol{K}=\boldsymbol{K} \boldsymbol{M}^{-1} \boldsymbol{C}
$$

then the damping matrix is diagonalized by the same transformation, which makes the undamped system diagonal [2]. The Eq. (11) is the commutative relationship. The general proportional damping matrix can be written in the explicit form [3]

$$
\boldsymbol{C}=\boldsymbol{M} \cdot f_{1}\left(\boldsymbol{M}^{-1} \boldsymbol{K}\right)
$$

where $f_{1}()$ is an analytic function of $\boldsymbol{M}^{-1} \boldsymbol{K}$.

For example in the case of Rayleigh damping this function is $f_{1}(x)=\alpha+\beta \cdot x$, where $\alpha, \beta$ are (usually real) constant material properties. For details see [4]. As mentioned in [5] and [6], the linear rheological models result in general proportional damping matrix.

\section{Singular value decomposition of FRF matrix}

By taking the singular value decomposition of the $F R F$ matrix at each spectral line $\omega$, the following expression is obtained

$\boldsymbol{H}(j \omega)=\boldsymbol{U}(j \omega) \cdot \boldsymbol{\Sigma}(j \omega) \cdot \boldsymbol{V}^{H}(j \omega)$,

where

$\boldsymbol{U}(j \omega)=\left[\begin{array}{llll}\boldsymbol{u}_{1}(j \omega) & \boldsymbol{u}_{2}(j \omega) & \ldots & \boldsymbol{u}_{N}(j \omega)\end{array}\right]$ left $\quad$ singular matrix (unitary),

$\Sigma(j \omega)=\left\langle\begin{array}{llll}\sigma_{1}(j \omega) & \sigma_{2}(j \omega) & \ldots & \left.\sigma_{N}(j \omega)\right\rangle\end{array} \quad\right.$ singular value matrix (diagonal matrix),

$\boldsymbol{V}(j \omega)=\left[\begin{array}{llll}\boldsymbol{v}_{1}(j \omega) & \boldsymbol{v}_{2}(j \omega) & \ldots & \boldsymbol{v}_{N}(j \omega)\end{array}\right]$ right singular matrix (unitary).

The $\Sigma(j \omega)$ contains the real and non-negative singular values in descending order. Singular Value Decomposition $(S V D)$ of $F R F$ matrix $\boldsymbol{H}(j \omega)$ can be written in vector summarization form

$$
\boldsymbol{H}(j \omega)=\sum_{i=1}^{N} \sigma_{i}(j \omega) \cdot \boldsymbol{u}_{i}(j \omega) \cdot \boldsymbol{v}_{i}^{H}(j \omega)
$$

In the practice of experimental modal analysis the Eq. (13) is limited to

$$
\boldsymbol{H}(j \omega)_{N_{o} \times N_{i}}=\boldsymbol{U}(j \omega)_{N_{o} \times N_{i}} \cdot \Sigma(j \omega)_{N_{i} \times N_{i}} \cdot \boldsymbol{V}^{H}(j \omega)_{N_{i} \times N_{i}} \cdot
$$




\section{Complex mode indication function and enhanced FRF}

The complex mode indicator function $(C M I F)$ technique and its application to multiple reference input testing is described in $[7,8,9,10,11]$. This $C M I F$ technique is a multiple degree of freedom technique based upon a modal model in the frequency domain. It estimates damped natural frequencies within the accuracy of the frequency-resolution and corresponding non-scaled mode shapes in a global sense. A continuation of the CMIF technique generates complex poles and modal scaling. The $C M I F$ is a plot of the log-magnitude of the $\Sigma(j \omega)$ singular values of the frequency response function matrix as a function of frequency (see Fig. 1).

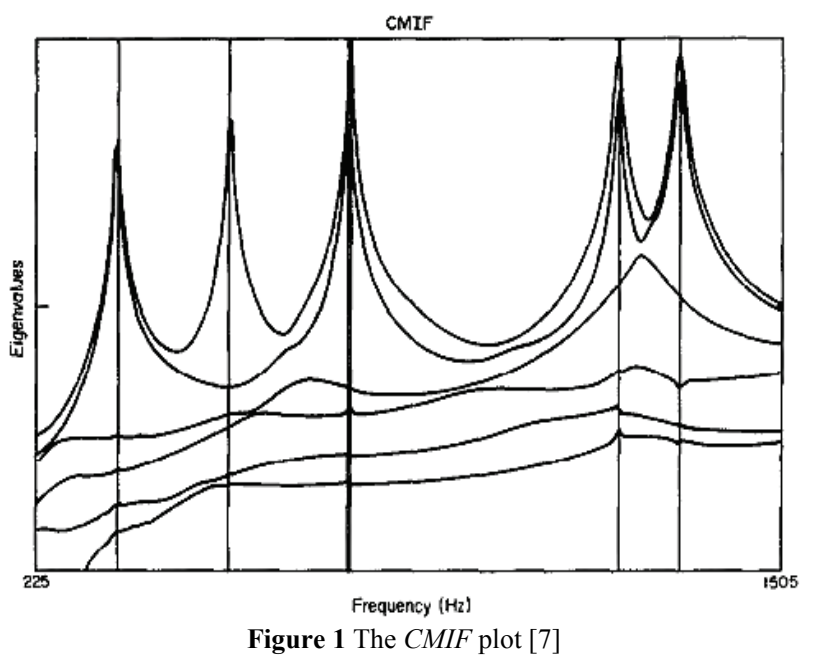

Eq. (9) shows the frequency response matrix as a function of the modal parameters. In absence of multiple roots, near resonance, as $\omega$ approaches the system pole $\lambda_{i}$, the quantity $a b s\left(1 /\left(j \omega-\lambda_{i}\right)\right)$ reaches a maximum. Since the quantities $\boldsymbol{X}$ and $\boldsymbol{L}$ are constant, the amplitude information of the frequency response matrix depends on these $1 /\left(j \omega-\lambda_{i}\right)$ terms. Similarly, in Eq. (13), since the columns of matrix $\boldsymbol{U}(\omega)$ and the rows of matrix $\boldsymbol{V}^{H}(\omega)$ are unit length vectors at each spectral line, the amplitude information as a function of frequency of the singular value decomposition formulation is contained in the singular value matrix $\Sigma(j \omega)$. Hence, if the $1 /\left(j \omega_{r}-\lambda_{i}\right)$ terms (absolute value of that) reach a maximum, so will the singular values: peaks in the CMIF plot locate the damped natural frequencies to the nearest spectral line.

Near resonance $\lambda_{i}=\delta_{i}+j v_{i}$ (when $\omega \rightarrow v_{i}$ ) the frequency response matrix is dominated by the corresponding term as in Eq. (7):

$\boldsymbol{H}(j \omega) \cong \frac{\vartheta_{i}^{-1} \boldsymbol{x}_{i} \boldsymbol{x}_{i}^{T}}{j \omega-\lambda_{i}}$.

Since the number of significant singular values at a specific spectral line indicates the number of linearly independent characteristics, i.e. modes, that contribute significantly to the content of the frequency response function matrix, near resonance the frequency response function matrix becomes:

$$
\boldsymbol{H}(j \omega) \cong \sigma_{1}(j \omega) \cdot \boldsymbol{u}_{1}(j \omega) \cdot \boldsymbol{v}_{1}^{H}(j \omega),
$$

where the subscript "1" indicates the first (=highest) singular value at spectral line $\omega \rightarrow v_{i}$.

Comparison of Eq. (16) and Eq. (17) shows, that the associated left singular vector approximates the $\boldsymbol{x}_{i}$ modal vector and that the associated right singular vecor approximates the $\vartheta_{i}^{-1} \boldsymbol{x}_{i}^{T}$ modal participation factor vector. Since $C M I F$ is a multiple reference algorithm, it can detect multiple roots. At these frequencies several modal vectors will dominate the response. This will show up by the existence of several significant singular values peaking at this frequency. CMIF can resolve repeated roots when the multiplicity of that are no greater than the number of references (number of columns of $\boldsymbol{H}(j \omega))$.

In the second phase, the CMIF method generates system poles and modal scale factors. It starts with the calculation of an enhanced frequency response function $(e F R F)$ for each mode $i$ making use of the left and right singular vectors at resonance [6]:

$e F R F_{i}(j \omega)=\boldsymbol{u}_{1}^{H}\left(j \omega_{i}\right) \cdot \boldsymbol{H}(j \omega) \boldsymbol{v}_{1}\left(j \omega_{i}\right)$,

where:

$\omega$ variable in total frequency range,

$\omega_{i}$ fixed frequency; place of mode $i ; \omega_{i}$ near $v_{i}$ damped

eigenfrequency,

$\boldsymbol{u}_{1}\left(j \omega_{i}\right), \boldsymbol{v}_{1}\left(j \omega_{i}\right)$ constant (first) singular vectors at $\omega_{i}$ frequency.

The $e F R F_{i}(j \omega)$ functions are the descriptions of a single-degree of freedom systems. Accurate damped natural frequencies and damping factors can be found by applying single-degree-of-freedom modal parameter estimation methods to each enhanced $e F R F_{i}(j \omega)$. Any single-degree of freedom parameter estimation algorithm (e.g. circle fit) produces an estimate for the system pole $\lambda_{i}$ and modal scale factor $\vartheta_{i}^{-1}$.

A number of other variants on the mode indicator function $(M I F)$ concept are also in use. Two are worth mentioning here: the $M v M I F$ (or multivariate $M I F$ ) and the $R M I F$ (real MIF). Detailed explanation of these can be found in the literature.

\section{Classical normal modes}

By comparing Eq. (9) and Eq. (13) and assuming classical normal modes the matrix $\boldsymbol{U}(j \omega)$ and matrix $\boldsymbol{V}(j \omega)$ in Eq. (13), can be written as:

$$
\begin{aligned}
& \boldsymbol{U}(j \omega)=\boldsymbol{U}_{0} \cdot \boldsymbol{\Phi}(j \omega)= \\
& =\left[\begin{array}{llll}
\boldsymbol{u}_{0,1} \cdot \mathrm{e}^{j \cdot \varphi_{1}(\omega)} & \boldsymbol{u}_{0,2} \cdot \mathrm{e}^{j \cdot \varphi_{2}(\omega)} & \ldots & \boldsymbol{u}_{0, N} \cdot \mathrm{e}^{j \cdot \varphi_{N}(\omega)}
\end{array}\right], \\
& \boldsymbol{V}(j \omega)=\boldsymbol{V}_{0} \cdot \boldsymbol{\Psi}(j \omega)= \\
& =\left[\begin{array}{llll}
\boldsymbol{v}_{0,1} \cdot \mathrm{e}^{j \cdot \psi_{1}(\omega)} & \boldsymbol{v}_{0,2} \cdot \mathrm{e}^{j \cdot \psi_{2}(\omega)} & \ldots & \boldsymbol{v}_{0, N} \cdot \mathrm{e}^{j \cdot \psi_{N}(\omega)}
\end{array}\right],
\end{aligned}
$$


where

$\boldsymbol{U}_{0} \in \boldsymbol{C}^{N \times N}$ and $\boldsymbol{V}_{0} \in \boldsymbol{C}^{N \times N}$ constant real-valued matrices, $\boldsymbol{\Phi}(j \omega)=\left\langle\begin{array}{llll}\mathrm{e}^{j \cdot \varphi_{1}(\omega)} & \mathrm{e}^{j \cdot \varphi_{2}(\omega)} & \ldots & \left.\mathrm{e}^{j \cdot \varphi_{N}(\omega)}\right\rangle \quad \text { diagonal }\end{array}\right.$ matrix, its diagonal elements represent phase shift,

$\boldsymbol{\Psi}(j \omega)=\left\langle\begin{array}{llll}\mathrm{e}^{j \cdot \psi_{1}(\omega)} & \mathrm{e}^{j \cdot \psi_{2}(\omega)} & \ldots & \left.e^{j \cdot \psi_{N}(\omega)}\right\rangle \quad \text { diagonal }\end{array}\right.$ matrix, its diagonal elements represent phase shift.

$\boldsymbol{U}(j \omega)$ is a unitary matrix, and $\boldsymbol{\Phi}^{H}(j \omega) \cdot \boldsymbol{\Phi}(j \omega)=\boldsymbol{I}$, thus $\boldsymbol{U}_{0}^{T} \cdot \boldsymbol{U}_{0}=\boldsymbol{I}$. Similarly, $\boldsymbol{V}(j \omega)$ is a unitary matrix, and $\boldsymbol{\Psi}^{H}(j \omega) \cdot \boldsymbol{\Psi}(j \omega)=\boldsymbol{I}$, thus $\boldsymbol{V}_{0}^{T} \cdot \boldsymbol{V}_{0}=\boldsymbol{I}$.

By substituting Eq. (19) into Eq. (13) we get a new form of the singular value decomposition:

$$
\boldsymbol{H}(j \omega)=\boldsymbol{U}_{0} \cdot \boldsymbol{\Phi}(j \omega) \cdot \Sigma(j \omega) \cdot \boldsymbol{\Psi}^{H}(j \omega) \cdot \boldsymbol{V}_{0}^{H} .
$$

$\boldsymbol{U}_{0}$ left singular matrix is $\boldsymbol{U}_{0}=\left[\begin{array}{llll}\boldsymbol{u}_{0,1} & \boldsymbol{u}_{0,2} & \ldots & \boldsymbol{u}_{0, N}\end{array}\right]$. Its columns are proportional with the mode shapes of the dynamical system. The product of the three matrices in the middle of Eq. (20) is a diagonal matrix, thus $\boldsymbol{H}(j \omega)$ in Eq. (20) can be written as:

$$
\boldsymbol{H}(j \omega)=\boldsymbol{U}_{0} \cdot \boldsymbol{\Xi}(j \omega) \cdot \boldsymbol{V}_{0}^{H},
$$

where $\boldsymbol{\Xi}(j \omega)=\left\langle\mathrm{e}^{j \varphi_{i}(\omega)} \cdot \sigma_{i}(j \omega) \cdot \mathrm{e}^{-j \psi_{i}(\omega)}\right\rangle$.

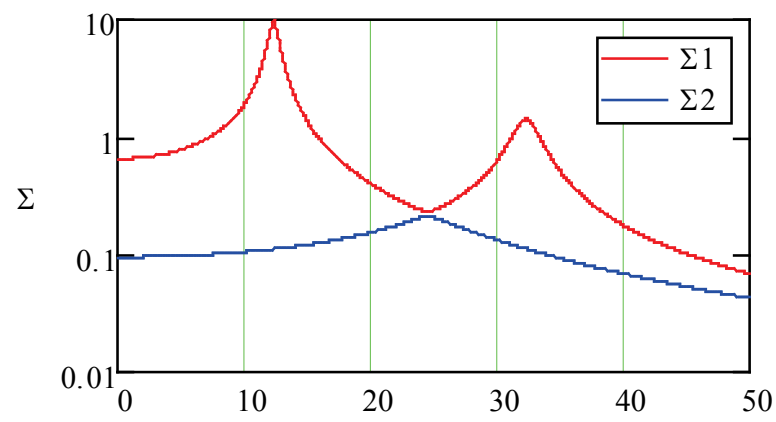

Frequency $[\mathrm{rad} / \mathrm{sec}]$

a)
The absolute value of the diagonal elements of $\boldsymbol{\Xi}(j \omega)$ equals $\sigma_{i}(j \omega)$, their phase shifts are $\varphi_{i}(\omega)-\psi_{i}(\omega)$.

\section{Singular vector tracking}

As known, the algorithms decomposing rectangular matrices by their singular values put the singular values in the diagonal of the $\Sigma(j \omega)$ matrix in descending order. The vector $\mathbf{u}_{i}$ is the left singular vector corresponding to the $i^{\text {th }} \sigma_{i}$ singular value and it is the $i^{\text {th }}$ column of the matrix $\boldsymbol{U}$. The vector $\boldsymbol{v}_{i}^{H}$ is the right singular vector corresponding to the $i^{\text {th }}$ singular value $\sigma_{i}$ and it is the $i^{\text {th }}$ row of the matrix $\boldsymbol{V}^{H}$ as it can be seen in Eq. (14). Singular value decomposition is performed for all measured frequencies $\omega_{r}$. The $\sigma_{i}$ corresponding to left singular vector $\boldsymbol{u}_{0, i}$ has a maximum in the vicinity of the damped natural frequency of the $i^{\text {th }}$ mode. Because of this in the vicinity of another eigenfrequency another $\boldsymbol{u}_{0, j}$ is the corresponding left singular vector for the biggest singular value. In other words the columns of the matrix $\boldsymbol{U}$ are alternating along the frequency, because the $S V D$ algorithm orders the singular vectors by the descending order singular values. Two left singular vectors swap over a frequency where the corresponding two singular values are equal. This frequency in Fig. 2 is the frequency of the anti-resonance.

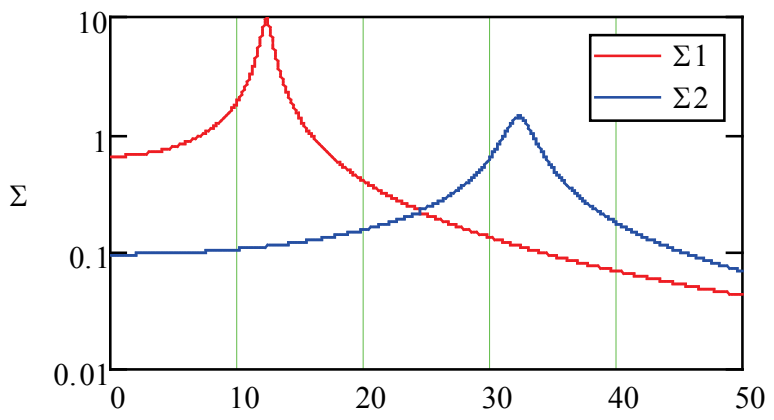

Frequency $[\mathrm{rad} / \mathrm{sec}]$

b)

Figure 2 Singular values of classical damped 2DOF model: a) Untracked; b) Tracked

Singular vector tracking is a method for reordering the singular vectors based on an arbitrary reference. When the structure has classical normal modes the tracking can be performed with the next formula.

$$
\begin{aligned}
& \boldsymbol{U}_{\text {Tracked }}(\omega)=\boldsymbol{U}_{\text {Untracked }}(\omega) \cdot \boldsymbol{T}\left(\omega, \omega_{\text {ref }}\right), \\
& \Sigma_{\text {Tracked }}(\omega)=\Sigma_{\text {Untracked }}(\omega) \cdot \boldsymbol{T}\left(\omega, \omega_{\text {ref }}\right), \\
& \boldsymbol{V}_{\text {Tracked }}^{H}(\omega)=\boldsymbol{T}\left(\omega, \omega_{\text {ref }}\right) \cdot V_{\text {Untracked }}^{H}(\omega),
\end{aligned}
$$

where

$\boldsymbol{U}_{\mathrm{U}}(\omega), \boldsymbol{\Sigma}_{\mathrm{U}}(\omega), \boldsymbol{V}_{\mathrm{U}}^{H}(\omega)$ the $S V D$ decomposition of $\boldsymbol{H}(\omega)$ at $\omega$ (the subscript $U$ means Untracked),
$\boldsymbol{U}_{\mathrm{T}}(\omega), \boldsymbol{\Sigma}_{\mathrm{T}}(\omega), \boldsymbol{V}_{\mathrm{T}}^{H}(\omega)$ are the reordered singular vectors and singular values (the subscript T means Tracked),

$\left.\boldsymbol{T}\left(\omega, \omega_{\mathrm{ref}}\right)=\left[T_{p, q}\right]=\left[\left(\boldsymbol{U}^{H}\left(\omega_{\mathrm{ref}}\right) \cdot \boldsymbol{U}_{\mathrm{U}}(\omega)\right)_{p, q}\right]\right]$

transformation matrix,

$\omega_{\text {ref }}$ reference frequency.

$\omega_{\text {ref }}$ is chosen by the corresponding frequency of the first peak of the first singular value function. After performing the Eq. (22) transformation for all $\omega$ frequencies, the column vectors of the tracked left singular matrix $\boldsymbol{U}_{\mathrm{T}}(\omega)$ and the corresponding singular values are in the same order as they are in the untracked left singular matrix $\boldsymbol{U}_{\mathrm{U}}\left(\omega_{\text {ref }}\right)$ for all frequencies (see 
Fig. 2b). The formula of Eq. (22) is only valid for $M D O F$ system with classical normal modes without overlapping modes.

\section{Developing a new complex aggregator FRF}

For obtaining the normal modes in a classical way, the following scalar function

$$
\operatorname{projFRF}(j \omega):=\boldsymbol{u}_{1}^{T}(j \omega) \cdot \boldsymbol{H}(j \omega) \cdot \boldsymbol{v}_{1}(j \omega),
$$

has to be taken as a projector. Here $\boldsymbol{u}_{1}(j \omega)$ and $\boldsymbol{v}_{1}(j \omega)$ are the first singular vectors. In Eq. (23) we substitute Eq. (21) into $\boldsymbol{H}(j \omega)$ furthermore we put $\boldsymbol{u}_{1}(j \omega)$ and $\boldsymbol{v}_{1}(j \omega)$ as they were written in Eq. (19).

$$
\begin{aligned}
& \boldsymbol{u}_{1}(j \omega)=\boldsymbol{u}_{0,1} \cdot \mathrm{e}^{j \varphi_{1}(\omega)} \rightarrow \boldsymbol{u}_{1}^{\mathrm{T}}(j \omega)=\mathrm{e}^{j \varphi_{1}(\omega)} \cdot \boldsymbol{u}_{0,1}^{T} \\
& \boldsymbol{v}_{1}(j \omega)=\boldsymbol{v}_{0,1} \cdot \mathrm{e}^{j \psi_{2}(\omega)} .
\end{aligned}
$$

It yields to

$$
\operatorname{projFRF}(j \omega)=\mathrm{e}^{j \varphi_{1}(\omega)} \cdot \boldsymbol{u}_{0,1}^{T} \cdot \boldsymbol{U}_{0} \cdot \boldsymbol{\Xi}(j \omega) \cdot \boldsymbol{V}_{0}^{H} \cdot \boldsymbol{v}_{0,1} \cdot \mathrm{e}^{j \psi_{1}(\omega)},
$$

and after performing the multiplication to the following expression

$$
\operatorname{projFRF}(j \omega)=\mathrm{e}^{2 j \varphi_{1}(\omega)} \cdot \sigma_{1}(j \omega) .
$$

The projector function defined in Eq. (25) is a complex function of frequency, its phase is the double of the phase of the left singular vector. The aggregator $F R F$, called $a F R F$ is defined as

$$
\operatorname{aFRF}(j \omega)=\mathrm{e}^{j \phi_{1}(\omega)} \cdot \sigma_{1}(j \omega),
$$

where $\phi_{1}(\omega)=\arg \left(\boldsymbol{u}_{1}^{T}(j \omega) \cdot \boldsymbol{u}_{1}(j \omega)\right) / 2$.

This describes the behaviour of a single degree of freedom system. Precise damped natural frequencies and damping factors can be found by applying single-degreeof-freedom modal parameter estimation methods to each peak of the $\operatorname{aFRF}(j \omega)$. Any single degree of freedom parameter estimation algorithm (e.g. circle fit) produces an estimate for the system pole $\lambda_{i}$.

Parameter estimation by circle fitting. An estimation of complex eigenvalue parameters can be based on the $a F R F$ and on the use of the least-squaremethod. The well-known approximate relationship that is used in this case is the following:

$$
a H\left(j \omega_{p}\right) \approx a H_{1}\left(j \omega_{p}\right)=\frac{P_{i}}{j \omega_{p}-\lambda_{i}},
$$

where

$a H(j \omega)$ approximation of the $\operatorname{aFRF}(j \omega)$ at $\omega$ frequency, $\omega_{p}$ the fixed frequency near the damped natural frequency $v_{i}$.

$\lambda_{i}$ the $i^{\text {th }}$ eigenvalue

$P_{i}$ the residue of the $i^{\text {th }}$ mode.

Reordering the Eq. (27) is given

$a H_{1}\left(j \omega_{p}\right) \cdot\left(j \omega_{p}-\lambda_{i}\right)=P_{i}$.

With measured data,

$a \hat{H}_{p} \cdot\left(j \omega_{p}-\lambda_{i}\right)=P_{i} \rightarrow a \hat{H}_{p} \lambda_{i}+P_{i}=j \omega_{p} \cdot a \hat{H}_{p}$

Repeating the above equation for several frequencies in the vicinity of the peak-frequency $\omega_{p}$,

$a \hat{H}_{p-s} \lambda_{i}+P_{i}=j \omega_{p-s} \cdot a \hat{H}_{p-s} s=-\hat{N}, \ldots, \hat{N}$

Matrix form of the equations above is

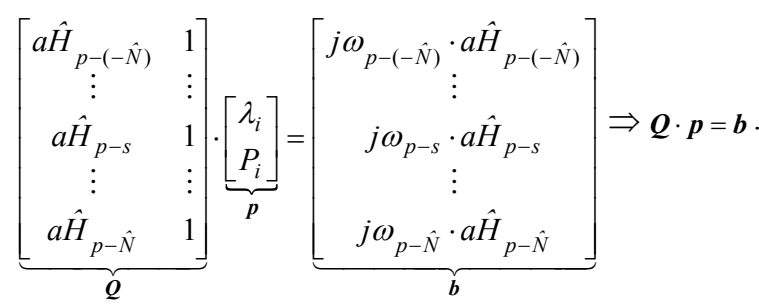

The above equation represents an over-determined set of linear equations that can be solved using any pseudoinverse or normal equations approach

$$
\boldsymbol{p}=\boldsymbol{Q}^{+} \boldsymbol{b}=\left[\begin{array}{c}
\lambda_{i, e s t} \\
P_{i, e s t}
\end{array}\right] \text {. }
$$

\section{Conclusions}

In this article the use of the singular value decomposition of the $F R F$ in order to estimate modal parameters was investigated. We found that the peaks of the singular value function estimate the damped natural frequency well. A new aggregated frequency response $a F R F$ was derived from the $e F R F$ known from the literature. The properties of the $a F R F$ function are:

- it is one complex function of frequency for the whole $M D O F$ system,

- $\quad$ each peak on the absolute value function indicates a mode, and the corresponding frequency of a peak approximates the damped natural frequency,

- this function contains phase information, thus every mode is represented as a modal circle on the Nyquist plot,

In the second Part of this article application of $a F R F$ function will be investigated. Parameter estimations will be performed on data of analytical models and experimental data. 


\section{Acknowledgment}

The authors acknowledge the support of the "New Széchenyi Plan Új Széchenyi Terv TÁMOP-4.2.1/B09/1/KMR-2010-0002".

\section{References}

[1] Pápai, F. Structural Diagnostic of Building and Materials Handling Machines by Application of Experimental Modal Analysis. // Budapest University of Technology and Economics. Faculty of Transportation Engineering. Department of Building Machines, Materials Handling Machines and Manufacturing Logistic. PhD Thesis / Budapest,2007

[2] Caughey, T. K. Classical Normal Modes in Damped Linear Dynamic System. Transaction of the ASME. // Journal of Applied Mechanics. 6(1960), pp. 269-271. DOI: 10.1115/1.3643949

[3] Adhikari, S. Damping modelling using generalized proportional damping. // Journal of Sound and Vibration. 293, 1-2(2006), pp. 156-170.

[4] Pápai, F.; Adhikai, S.; Wang B. T. Estimation of modal Dampings for Unmeasured Modes. // Slovak Journal of Civil Engineering. 20, 4(2012), pp. 17-27. DOI: 10.2478/v10189-012-0018-3

[5] Pápai, F. Investigation of Damping Modeling of dynamical System with Classical Normal Modes. // Proceedings of MAMEK XI Hungarian Mechanical Conference ISBN: 978-963-661-975-6/ Miskolc, 2011

[6] Pápai, F.; Szűcs, I. Modal Analysis of Large Structures with High Importance and Value. // Proceedings of MAMEK XI Hungarian Mechanical Conference ISBN: 978-963-661975-6/ Miskolc, 2011

[7] Shih, C. Y.; Tsuei, Y. G.; Allemang, R. J.; Brown, D. L. Complex Mode Indicator Function and Its Applications to Spatial Domain Parameter Estimation. // Mechanical Systems and Signal Processing. Z4(1988), pp. 367-377. DOI: 10.1016/0888-3270(88)90060-X

[8] Shih, C. Y.; Tsuei, Y. G.; Allemang, R. J.; Brown, D. L. Complex Mode Indicator Function and Its Applications to Spatial Domain Parameter Estimation. // Proceedings, Int. Modal Analysis Conference /1989, pp. 533-540.

[9] Phillips, A. W.; Allemang, R. J.; Fladung, W. A. The Complex Mode Indicator Function (CMIF) as a Parameter Estimation Method. // Proceedings, SEM IMAC XVI. International Modal Analysis Conference / Bethel, 1998, pp. 705-710.

[10] Prader, J. B. Rapid Impact Modal Testing for Bridge Flexibility: Towards Objective. Evaluation of Infrastructures. // Drexel University PhD Thesis, 2012

[11] Allemang, R. J.; Brown, D. R. A Complete Review of the Complex Mode Indicator Function (CMIF) with Applications. // Proceedings of ISMA Conference / 2006.

\section{List of used Symbols}
$j$ imaginary unit
$N$ degree-of-freedom of the system
$N_{m}$ number of modes
$N_{i}$ number of inputs
$N_{o}$ number of outputs
$i$ mode number
$I$ identity matrix
$\boldsymbol{H}(j \omega)$ FRF (Frequency Response Function) matrix

\author{
$\boldsymbol{A}^{H}$ Hermitian (conjugate transpose) of a matrix $\boldsymbol{A}$ \\ $A^{*}$ conjugate of a matrix $A$ \\ $\boldsymbol{A}^{T}$ transpose of a matrix $\boldsymbol{A}$ \\ $\boldsymbol{A}^{+}$pseudo-inverse of a matrix $\boldsymbol{A}$ \\ $\Lambda$ eigenvalue matrix (diagonal) \\ $\Sigma \quad$ singular value matrix (diagonal) \\ $\boldsymbol{U}$ left singular matrix (unitary) \\ $\boldsymbol{V}$ right singular matrix (unitary) \\ $\boldsymbol{u}$ left singular vector \\ $v$ right singular vector \\ $\boldsymbol{x}_{i}$ modal vector for mode $i$ \\ $\boldsymbol{M}$ mass matrix \\ $\boldsymbol{C}$ damping matrix \\ $\boldsymbol{K}$ stiffness matrix \\ $F R F$ Frequency Response Function \\ eFRF enhanced $F R F$ \\ $a F R F$ aggregated $F R F$ \\ \langle\rangle diagonal matrix
}

\section{Authors' addresses}

Ferenc Pápai, Assoc. Prof. PhD, Dr.

Budapest University of Technology and Economics,

Faculty of Transportation Engineering and Vehicle Engineering, Department of Vehicle Elements and Vehicle-Structure Analysis H-1111 Budapest, Stoczek u. 2., Hungary

E-mail: papai@modal.hu

István Szücs, Assoc. Prof. PhD, Dr.

University of Pécs, Pollack Mihály Faculty of Engineering and Information Technology, Department of Infrastructure and Technical Geoinformatics H-7624 Pécs, Boszorkány u. 2., Hungary

E-mail: dr.szucsistvan@t-online.hu 